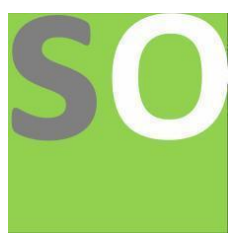

Article title: Oil Spill Cleanup Techniques - A bibliographic analysis of the latest methods and their efficiency Authors: Nurana Ismayilova[1]

Affiliations: French-Azerbaijani University ,Baku, Azerbaijan[1]

Orcid ids: 0000-0003-0431-4333[1]

Contact e-mail: nurana.ismayilova@ufaz.az

License information: This work has been published open access under Creative Commons Attribution License $\mathrm{http}: / / c r e a t i v e c o m m o n s . o r g / l i c e n s e s / b y / 4.0 /$, which permits unrestricted use, distribution, and reproduction in any medium, provided the original work is properly cited. Conditions, terms of use and publishing policy can be found at https://www.scienceopen.com/.

Preprint statement: This article is a preprint and has not been peer-reviewed, under consideration and submitted to ScienceOpen Preprints for open peer review.

DOI: 10.14293/S2199-1006.1.SOR-.PPMMDHY.v1

Preprint first posted online: 26 September 2021

Keywords: Oil Spill, Cleanup Techniques, Eco-friendly Methods 


\title{
Oil Spill Cleanup Techniques - A review of the latest methods and their efficiency
}

\begin{abstract}
:
Oil spills have become a center of concern for scientists especially these days due to climate change and environmental health. The traditional methods seem to be unable to intensively fight with the exponentially increasing amounts of spillage and the research for new methods is urgent. The paper aims at reviewing the existing techniques of the removal of oil spills alongside collecting and analyzing the efficiency of the latest and eco-friendly methods of the cleanup. It also compares the current situation in the different parts of the world and the methods used by the developed countries to fight this environmental disaster.
\end{abstract}

Keywords: Oil Spill, Cleanup Techniques, Eco-friendly Methods, Natural Sorbents

\section{Introduction:}

The Oil spills appeared to be the most noteworthy ocean and stream contamination. For the most part, oil is inadvertently released during extraction, conveyance, stockpiling, and usage. Some of the largest oil spills are shown in Table 1.

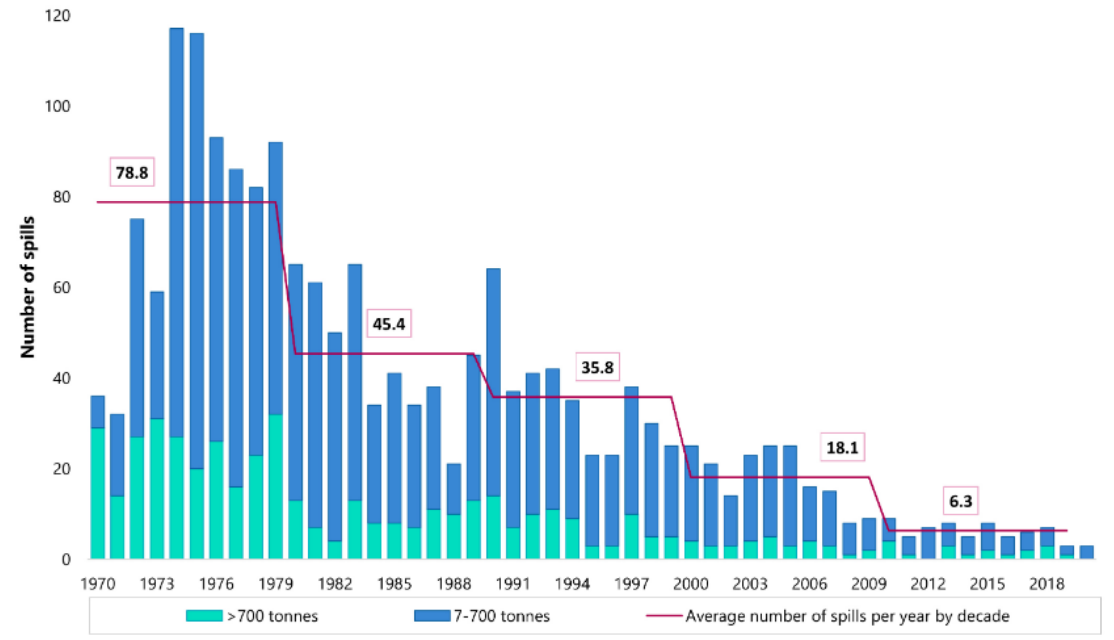

Table 1. Number of oil spills over the past 48 years. [1] 
It may very well be expressed lately that the pattern has changed significantly. A large part of unrefined petroleum release happened in the streams. About 5 millions huge loads of crude oil items are shipped per annum moderately across the sea internationally. Some of the conventional methods that have been utilized in recent years are : the utilization of substance dispersants, control (oil blasts), mechanical recuperation (skimmers and separators) and bioremediation. The systems and endeavors for cleanup exercises rely on different factors, for example, water temperature, proximity to shoreline, spill volume, oil type and thickness, waves, climate, flows and reaction speed [2]. These variables possess limitations, which limits their usage. The requirement for environmentally friendly and savvy regular sorbents couldn't be more overemphasized. Although various ingenious methods have been proposed namely, usage of hair as hair as an absorbent, Nasa's "frozen smoke" to soak up oil spills as an "aerogel sponge", petrogel - super absorbent polymer and so on, these suggestions have certain limitations for the usage to a wide-extent. Certain factors such as hydrophobicity and oleophilicity, rate of retention, economical feasibility, biodegradability, absorption capability should be satisfied in the long run.

\section{Effects of Oil Spills:}

The pollutants (oil) are regularly and accidentally released into the water bodies. This may include the destruction of oil stockpiling tanks, penetrating oil from tanks on the rig, at war times, regular events and damaged pipelines which eventually harm the environment. One can observe the most common causes of oil spillage in Table 2.

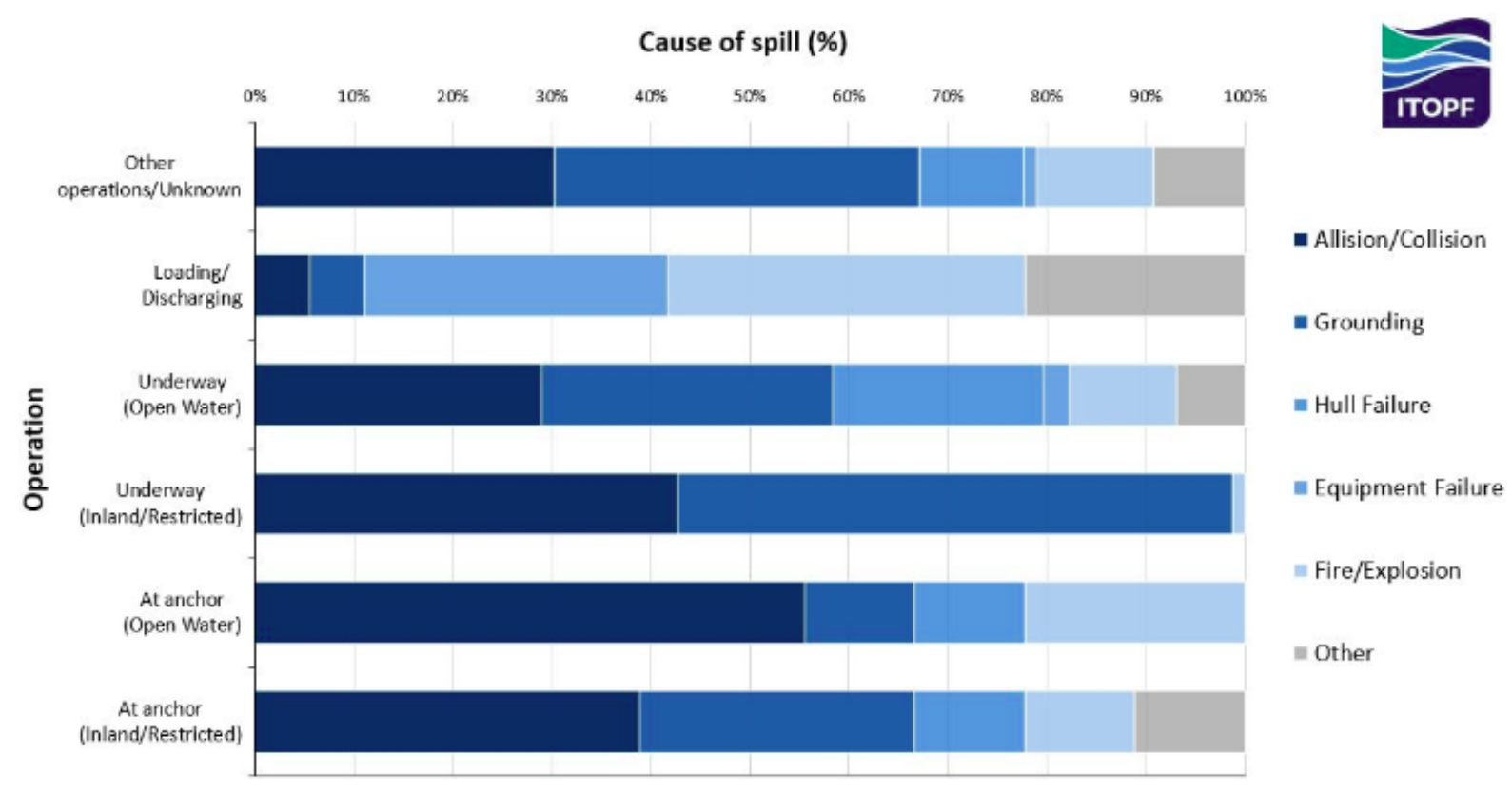

Table 2. Causes of spill [1] 
In the 1967 Torrey Canyon episode 25,000 birds were killed including more than 3 thousand ocean birds. The Buzzard Bay episode in Massachusetts in 1968 brought about the killing of huge quantities of fish; for this situation, the oil was light with high harmfulness and was parted into shallow water [3]. The British Petroleum Gulf of Mexico's occurrence asserted the assessed lives of 997 birds, 400 ocean turtles and 47 Mammals [4]. Besides, oil slick might result in oxidative impact that influences biomolecules, extreme decrease of ocean plants, on the grounds that any adverse consequences on photosynthetic living beings, will impact the number of inhabitants in others, which will therefore, influence different species in the environment [4-6]. Buildup of oil slick throughout a significant stretch of time doesn't allow the recuperation of the environment [5]. Oil-covered birds are a general image of natural harm unleashed by oil slicks. A few types of shore birds may escape by migrating in the event that they sense risk on schedule, however ocean birds that swim and jump for their food are probably going to be canvassed in oil following a spill [7]. The 2010 BP Deepwater Horizon seaward oil slick in the Gulf of Mexico, for instance, happened during prime mating and settling season for some bird and marine species, and long haul ecological results of that spill will not be known for quite a long time.

The Exxon Valdez oil slick killed more than two thousand ocean otters, three hundred harbor seals, and up to twenty executioner whales. In the years after the Exxon Valdez spill, researchers noted higher passing rates among ocean otters and different species influenced by the spill and hindered development or other harm among extra species [8-10].

\section{Prevention Techniques:}

Forestalling oil spills is the best procedure for keeping away from possible harm to human wellbeing and to the climate. Clean up is tedious and costly, however costs are minor contrasted with the adverse consequence on an association's image and picture. Redundant oil spills, even minor ones, lead to expanded investigation from natural controllers. Counteraction measures are expected to keep away from the arrival of oil into the climate and depend on: [10-13]

- early warning frameworks;

- satellite checking frameworks.

An early admonition framework can recognize spills and holes of oil-on-water. It can give 24-hour continuous identification of even little amounts of hydrocarbons and is solid in unpleasant climate or night conditions, when conventional investigation procedures are ineffectual. Early discovery empowers reacting specialists to make quick restorative moves to pause and contain a spill, subsequently offering a powerful method for limiting the natural and monetary effect of a spill occasion [12]. 
Through satellites a worldwide inclusion is conceivable rather than the more nearby inclusion of an airplane. To forestall and control oil leakage, it would be beneficial as a satellite checking framework, in view of the utilization of one of the accessible stations of Galileo, the new European Satellite Navigation System. It will permit a fast and effective reconnaissance and identification of oil slicks that today is unthinkable. Among the counteraction methods ought to be additionally considered what predicted in the supposed "Erika bundles" [14]. In reality, following the Erika mishap, the European Commission arranged measures to increment oceanic security. In March 2000 the Commission embraced a first arrangement of recommendations (Erika I bundle), followed by a second one in December 2000 (Erika II bundle). The Erika I bundle supports the review system and raises the quality necessities for the order of social orders. It likewise set a plan for eliminating single-body oil big haulers. Truly twofold structure big haulers offer better security for the climate, in case of a mishap. The Erika II bundle sets up an European Maritime Safety Agency, liable for further developing requirements of the EU rules on sea security. In addition, the bundle builds up an observation and data framework to further develop vessel checking in EU waters, proposes an instrument to further develop pay for survivors of oil slicks and raises as far as possible on the sums payable in case of significant oil slicks in EU waters.

\section{Cleanup Methods:}

The principal sorts of methodology by and by available are :

- skimmers;

- dispersants;

- in-situ burning;

- bioremediation. [14]

Exactly when used in recovering oil, impacts are consistently maintained by a level arm, expanding clearly off one or the different sides of a vessel.

Skimmers are contraptions used to recover floating oil from the water surface. They may act normally and may be used from shore or worked from vessels [15].

Dispersants are sprayed on the oil spillage in order to split the oil into manageable parts which might diffuse into water. They are applied to the water surface to isolate surface oil slicks and work with the improvement of oil particles into the water section. Showering dispersants might be the main method for eliminating oil from the ocean surface, especially when mechanical recuperation is absurd. Dispersants utilized today are substantially less poisonous than those 
utilized before. In-situ consumption includes the start and controlled burning of oil; it is normally utilized related to mechanical recuperation on untamed water.

Heat proof blasts are frequently used to gather and move the oil into a smooth that is sufficiently thick to consume. This method can possibly eliminate a lot of oil from the water surface. There are various issues restricting the practicality of this method such as, the age of huge amounts of smoke, the development and conceivable sinking of incredibly thick and thick buildups and security concerns [16].

Oil, similarly as other typical substances, will biodegrade all through some unclear time period into clear blends. The term bioremediation shows a movement of cycles used to accelerate customary biodegradation [17]. Bioremediation experts are frequently applied to outstanding oil on shorelines, for long stretch cleanup conditions. Regularly, profound oil is first killed before bioremediation is embraced. Lamentably the practical use of bioremediation is restricted. In particular, bioremediation should not be used on oil on the sea surface, since any materials added are most likely going to be immediately debilitated and lost from the smooth. Standard biodegradation can be most useful accelerated when bioremediation is used shorewards.

A wide range of issues emerge during the tidy up stage. For instance, blasts are useful in spill control in great climate conditions yet they are not really viable in difficult situations; after the skimmers have completed their work, there is as yet a little amount of oil left which should be scattered utilizing, for instance, substance dispersants. Dispersants might debase marine life through the accumulation of oil on the sea bed [18].

\section{Components on choosing the cleanup strategy :}

Clearly, there is a monstrous need to plan and discover the most reasonable technique for battling against oil spillage and this prompted the idea of a few factors that specialists use to think of the most helpful arrangement in a crisis. It is possible to distinguish three series of measures that must be applied in succession; this implies that procedures ought to most importantly conform to the standards of the principal type, after that they should meet the second sort rules and eventually they ought to fulfill the third factors :

- primary models;

- specialized measures;

- financial ecological rules [19]

Factors such as: 
- the time of intercession;

- the typology of spilled oil;

- conditions adrift;

fall inside the fundamental measures.

A vital factor while picking the best accessible procedures, to confront an oil slick, is the hour of mediation. Another choice aiding factor is the substance properties of the spillage.

The principle oil typologies are:

- light oils;

- medium oils;

- weighty oils.

A few procedures, for example, those dependent on the utilization of dispersants affect substantial unrefined oils. In reality, substantial rough oils don't scatter just as light and medium oils .Another thing to be considered is the circumstance in the ocean : there are various techniques to eliminate contingent upon the ocean conditions like quiet, uneven, snow covered and so forth. For example, in-situ consumption is best in the event of an ice-shrouded sea. Actually, in extreme ocean conditions, the oil will be lowered by breaking waves, forestalling direct contact between the dispersant and the oil. 


\begin{tabular}{|c|c|c|c|c|c|c|c|c|}
\hline \multicolumn{2}{|c|}{ CRITERIA } & \multicolumn{7}{|c|}{ BAT } \\
\hline & & है & 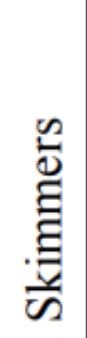 & $\begin{array}{l}\stackrel{\mathscr{Z}}{0} \\
\stackrel{0}{0} \\
\ddot{0}\end{array}$ & 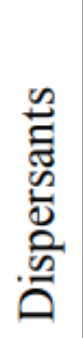 & 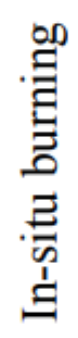 & 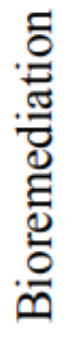 & 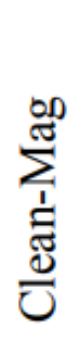 \\
\hline \multirow{2}{*}{$\begin{array}{ll}\text { Time } & \text { of } \\
\text { intervention }\end{array}$} & Prompt & $\mathrm{X}$ & $\mathrm{X}$ & $X$ & $X$ & $\mathrm{X}$ & & $\mathrm{X}$ \\
\hline & Next & $\mathrm{X}$ & $\mathrm{X}$ & $\mathrm{X}$ & & & $\mathrm{X}$ & $\mathrm{X}$ \\
\hline \multirow{3}{*}{$\begin{array}{l}\text { Typology } \\
\text { spilled oil }\end{array}$} & Light & $\mathrm{X}$ & $\mathrm{X}$ & $X$ & $\mathrm{X}$ & $\mathrm{X}$ & $\mathrm{X}$ & $\mathrm{X}$ \\
\hline & Medium & $\mathrm{X}$ & $\mathrm{X}$ & $\mathrm{X}$ & $\mathrm{X}$ & $\mathrm{X}$ & $\mathrm{X}$ & $\mathrm{X}$ \\
\hline & Heavy & $\mathrm{X}$ & $\mathrm{X}$ & $\mathrm{X}$ & & $\mathrm{X}$ & $\mathrm{X}$ & $\mathrm{X}$ \\
\hline \multirow{3}{*}{ Conditions at sea } & Calm & $\mathrm{X}$ & $\mathrm{X}$ & $\mathrm{X}$ & $\mathrm{X}$ & $\mathrm{X}$ & & $\mathrm{X}$ \\
\hline & Choppy & & & & & & & $\mathrm{X}$ \\
\hline & Icy & $\mathrm{X}$ & $\mathrm{X}$ & & & $\mathrm{X}$ & & $\mathrm{X}$ \\
\hline
\end{tabular}

Table 3. Criterias of BAT [19]

Subsequently, specialized standards have been recognized. Simply specialized attributes are:

- real accessibility;

- possibility;

- similarity with different methods.

Another significant trademark is the method's attainability, as far as coordinations and other functional angles. It is fundamental to really take a look at the presence of reasonably prepared administrators and offices on the side of the strategy, imperative to the procedure's doing. At last ought not to be ignored the similarity of the strategy, under assessment, with different ones utilized with regards to the tasks executed to look out for the oil slick [20].

\section{Challenges in oil spill cleanup procedure:}

Oil slick tidy up is a thorough exercise because of a few factors that impact its control. Several of them are described below : 


\section{Salinity:}

Salinity of the ocean is defined as one gram of salt per one kilogram of water. Increase in salinity increases water density and thus reduces the interfacial tension. The decrease in surface tension, therefore, enhanced oil recovery from the water as shown in Table 4.

\begin{tabular}{|c|c|c|}
\hline $\begin{array}{c}\text { Simulated Seawater } \\
\left(\mathrm{kgNaCl} / \mathrm{m}^{3}\right)\end{array}$ & $\begin{array}{c}\text { Density } \\
\left(\mathrm{kg} / \mathrm{m}^{3}\right)\end{array}$ & $\begin{array}{c}\text { Interfacial Surface } \\
\text { Tension }(\mathrm{mN} / \mathrm{m})\end{array}$ \\
\hline 0.0 & 996 & 48.0 \\
\hline 10.0 & 998 & 45.0 \\
\hline 20.0 & 1010 & 27.2 \\
\hline 30.0 & 1020 & 25.5 \\
\hline
\end{tabular}

Table 4. Salinity Data [20]

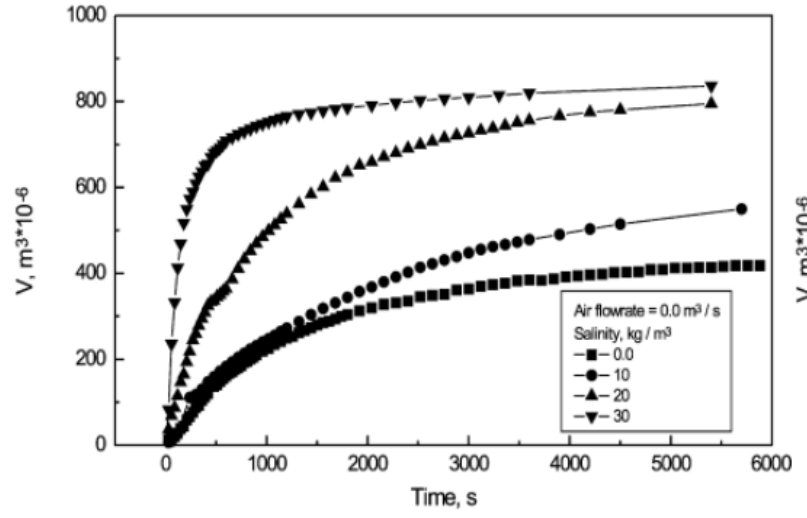

a.

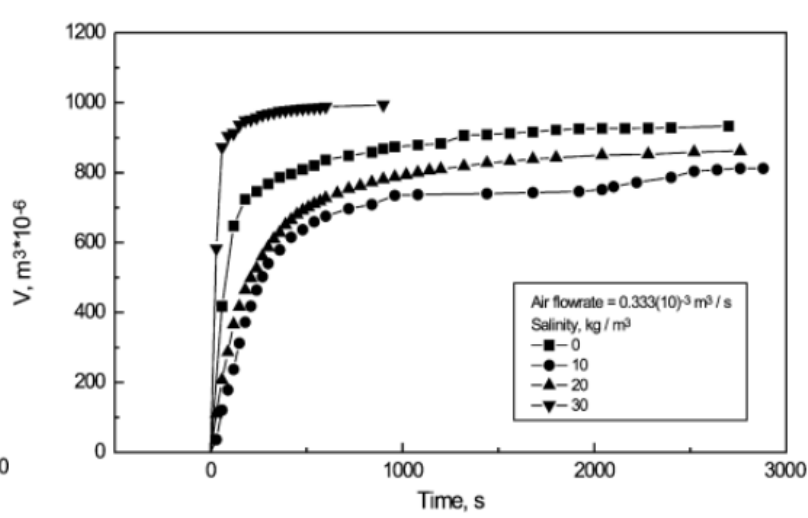

b.

Fig. 3 : The rate of oil spill clean up using vacuum technique [20]:

a- Effect of salinity on calm water;

b- Effect of salinity on turbulent water.

\section{Temperature:}

Temperature is one of the most important factors because it is changeable depending on the season and location. High temperature enhances evaporation of lighter parts of oil because increase in temperature reduces oil viscosity; however, the nature of the oil also plays a significant role. As the temperature decreases, the solubility of the oil decreases as well. The heavier fraction on the water surface tends to hinder combustion and the effectiveness of surfactant [21].

Wave height: Sea conditions influence oil tidy up hugely, when the climate is unpleasant, the water surface is disturbed. This agitation prevents the viability of control utilizing a blast. This is on the grounds that during this period, a portion of the oil escapes from the control [22]. 
Surfactants: These are compound added substances that bring down the interfacial surface strain among oil and water. It is utilized as a dispersant for oil slick tidy up. Along these lines, the oil drops are diminished to more modest drops, which become denser and subsequently, sink to the ocean bed.

\section{Conclusion:}

The paper analyzed the effects of oil spill on the environment, collected and compared the existing methods of preventing and removal of oil leakage from waters using available international literature. It became obvious that the need for extensive research on the new technologies and the possibility of wide usage. Further investigation of the innovative techniques and their integration with the available methods ought to be the primary branch of the research in this area.

\section{References:}

1. Choi, H.M., R.M. Cloud, 1992. Natural sorbents in oil spill cleanup, Environmental Science and Technology, 26: 772-776.

2. Carls, M. G., Rice, S.D, Hose, J.E. (1999) 'Environmental Texicology Chemistry', Environmental Science and Technology, 18, pp. 481-495.

3. Clark, R. B. (2001) Marine Pollution. Clarendon Press, Oxford: England.

4. http://wwf.no/dette_jobber_med/hav_og_kyst_wwfs_frivillige_oljevern/oljeulykker_lang s_no 1971.

5. "Water Marks: Louisiana Coastal Wetlands Planning, Protection and Restoration News." Louisiana Coastal Wetlands Planning, Protection and Restoration Act of 1900.

6. Short, Jeffrey W., et al. "Slightly Weathered Exxon Valdez Oil Persists in Gulf of Alaska Beach Sediments after 16 Years." Environmental Science \& Technology, vol. 41, 2007, pp: 1245-1250., doi:10.1021/es0620033

7. John, R.G., 2001. Hydrophobic aerogels for oil-spill clean-up? Intrinsic absorbing properties Energy sources,Part A. Recovery utilization and environmental effect

8. Mathewson, Paul D., et al. "Experimental and Modeled Thermoregulatory Costs of Repeated Sublethal Oil Exposure in the Double-Crested Cormorant, Phalacrocorax 
auritus." Marine Pollution Bulletin, vol. 135, 2018, pp. 216-223., doi:10.1016/j.marpolbul.2018.07.003

9. King, Mason D., et al. "Effects of Petroleum Exposure on Birds: A Review." Science of The Total Environment, vol. 755, part 1, 2021, doi:10.1016/j.scitotenv.2020.142834

10. "Questions and Answers About the Spill." Exxon Valdez Oil Spill Trustee Council.

11. Fingas, Merv F., editor. Handbook of Oil Spill Science and Technology (First Edition). John Wiley \& Sons, Inc., 2015.

12. Fukuyama, Allan K., et al. "Status of Intertidal Infaunal communities Following the Exxon Valdez Oil Spill in Prince William Sound, Alaska." Marine Pollution Bulletin, vol. 84, 2014, pp. 56-59, doi:10.1016/j.marpolbul.2014.05.043

13. Harwell, Mark A., and John H. Gentile. "Assessing Risks to Sea Otters and the Exxon Valdez Oil Spill: New Scenarios, Attributable Risk, and Recovery." Human and Ecological Risk Assessment: An International Journal, vol. 20, 2014, pp. 889-916, doi:10.1080/10807039.2013.828513

14. Quintana-Rizzo, Ester, et al. " $\delta 13 \mathrm{C}$ and $\delta 15 \mathrm{~N}$ in Deep-Living Fishes and Shrimps after the Deepwater Horizon Oil Spill, Gulf of Mexico." Marine Pollution Bulletin, vol. 94, 2015, pp. 241-250, doi:10.1016/j.marpolbul.2015.02.002

15. "Plan for Deepwater Horizon Oil Spill Natural Resource Injury Restoration: An Overview." National Oceanic and Atmospheric Administration.

16. Graham, P., 2010. Deep sea oil spill clean-up techniques: Applicability, trade-offs and advantages Prquest discovery guides.

17. Harms, Craig A., et al. "Crude Oil and Dispersant Cause Acute Clinicopathological Abnormalities in Hatchling Loggerhead Sea Turtles (Caretta caretta)." Frontiers in Veterinary Science, vol. 6, 2019, doi:10.3389/fvets.2019.00344

18. "Catastrophic Spill Event Analysis: High-Volume, Extended-Duration Oil Spill Resulting from Loss of Well Control on the Gulf of Mexico Outer Continental Shelf." Bureau of Ocean Energy Management. U.S. Department of the Interior.

19. Clean-up technique; International Tanker Owners Pollution Federation Limited, http://www.itopf.org/containment.html 
20. The use of chemical dispersants to treat oil spills; Technical Information Paper; International Tanker Owners Pollution Federation Limited, http://www.itopf.com/tip4.pdf

21. http://www.teipir.gr/cleanmag

22. 530 Water Resources Management IV www.witpress.com, ISSN 1743-3541 (on-line) WIT Transactions on Ecology and the Environment, Vol 103, (C) 2007 WIT Pres 